JEAN CARLOS PIMENTEL DOS SANTOS

\title{
A TUTELA PROVISÓRIA COMO MECANISMO PARA ALCANÇAR À RAZOÁVEL DURAÇÃO DO PROCESSO
}

\author{
DISSERTAÇÃO DE MESTRADO
}

Orientador: Prof. Dr. Rodrigo Reis Ribeiro Bastos

UNIVERSIDADE DE SÃO PAULO

FACULDADE DE DIREITO

SÃO PAULO

2020 

JEAN CARLOS PIMENTEL DOS SANTOS

\section{A TUTELA PROVISÓRIA COMO MECANISMO PARA ALCANÇAR À RAZOÁVEL DURAÇÃO DO PROCESSO}

Dissertação apresentada à Banca Examinadora do Programa de Mestrado em Direito do Estado Interinstitucional da Universidade de São Paulo USP e Centro Integrado de Ensino Superior do Amazonas - CIESA, como exigência parcial para obtenção do título de Mestre em Direito.

Orientador: Prof. Dr. Rodrigo Reis Ribeiro Bastos. Área de concentração: Direito do Estado. 
AUTORIZO A REPRODUÇÃO TOTAL OU PARCIAL DESTE TRABALHO, POR QUALQUER MEIO CONVENCIONAL OU ELETRÔNICO, PARA FINS DE ESTUDO E PESQUISA, DESDE QUE CITADA A FONTE.

Assinatura: Data

Catalogação na Publicação (CIP)

Biblioteca da Faculdade de Direito da USP Faculdade de Direito da Universidade de São Paulo

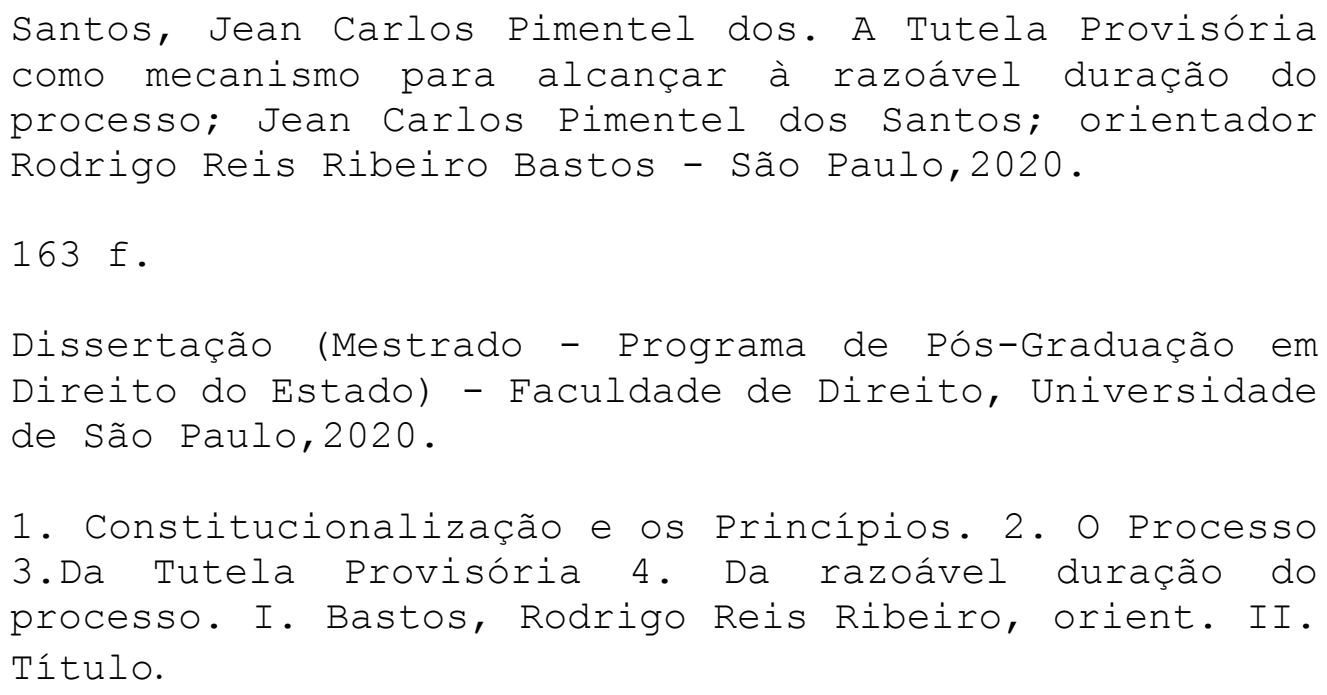


Nome: Jean Carlos Pimentel dos Santos

Titulo: A Tutela Provisória como mecanismo para alcançar à razoável duração do processo.

Dissertação apresentada ao Programa de Pós-Graduação em Direito do Estado da Faculdade de Direito da Universidade de São Paulo para obtenção do título de Mestre. Aprovado em:

\section{Banca Examinadora}

Orientador: Prof. Dr.

Instituição: Assinatura:

Prof. Dr. Instituição:

Julgamento: Assinatura:

Prof. Dr. Instituição: Julgamento: Assinatura:

Prof. Dr. Instituição:

Julgamento: Assinatura: 


\section{DEDICATÓRIA}

Aos meus pais, José Carlos e Conceição, e toda a minha família, pela presença sempre marcante em minha vida, pelo apoio e estímulo à minha formação acadêmica e profissional, pelo exemplo de vida e maravilhoso convívio que me proporcionam.

À minha avó, Aberydes (in memoriam), com carinho e saudades.

À minha esposa, Sissy, pela força e tranquilidade que sempre me transmitiu, e atuações em prol de meu crescimento pessoal e profissional.

Ao meu filho Juan, pela seu entusiasmos e companhia de sempre. 


\section{AGRADECIMENTO}

Ao meu orientador, Professor Dr. Rodrigo Reis Ribeiro Bastos, pela segurança, apoio, inteligência e amizade com que conduziu a elaboração desta dissertação.

Aos Mestres, pelo conhecimento ministrado durante o curso.

Aos amigos e colegas de curso, que proporcionaram um caminho menos árduo, com companheirismo e atitudes.

A todos que, diretamente ou indiretamente, contribuíram e colaboraram na realização deste trabalho.

A Associação dos Magistrados do Estado do Amazonas - Amazon, por operacionalizar e viabilizar o convênio com o CIESA. 
" A justiça atrasada não é justiça; senão injustiça qualificada e manifesta"

Rui Barbosa. 
SANTOS, Jean Carlos Pimentel dos. A Tutela Provisória como mecanismo alcançar à razoável duração do processo. 2020. 163 f. Mestrado - Faculdade de Direito, Universidade de São Paulo, São Paulo, 2020.

\section{RESUMO}

Estudaremos as Tutelas Provisórias, desde do seu aparecimento até a nova roupagem dada pelo novo diploma processual civil, onde possibilitou magnífica inovação, traduzida na possibilidade de o julgador antecipar, provisoriamente e mediante requisitos, aquilo em que poderá redundar a sentença, como mecanismo para satisfazer o direito fundamental à razoável duração do processo. A Tutela provisória, aperfeiçoada e profundamente alterada pela vigência do Novo Código de Processo Civil acelerou o processo e, sobretudo, limitou, tanto quanto possível, o uso, por parte do réu, da dinâmica normalmente arrastada do processo para prolongar por largo tempo a efetiva prestação jurisdicional, ou ao menos possibilitou, pela tutela da evidência, um melhor equilíbrio do ônus temporal suportado pelas partes. Abordaremos desde da constitucionalização do processo e os princípios derivados desse fenômeno, positivando direito e garantias fundamentais, entre outros a razoável duração do processo, incorporado pela emenda 45/2004, e introduzido do artigo $5^{\circ}$, inciso LXXVIII, que aliado o direito de ação inserto no inciso XXXV, passam dar sustentáculo constitucional as Tutela Provisórias. Pretende-se demonstrar o processo como instrumento através do qual será efetivada a tutela jurisdicional, os antecedentes históricos, a morosidade, e estudo completo da nova tutela provisória, enfatizando a sua origem histórica, evolução, conceituação, espécies, pressupostos, reversibilidade e revogação, fungibilidade, momento de concessão, a estabilização da tutela, e como dar sua utilização em outros países, relacionando-as com o direito fundamental à razoável duração do processo, pelo estudo do tempo processual e o contexto mundial, inovações e estrutura que possam garantir a efetiva e célere prestação jurisdicional.

PALAVRAS-CHAVE: Tutela Provisória. Direito fundamental. Razoável duração do processo. Novo Código de Processual Civil. 
SANTOS, Jean Carlos Pimentel dos Santos. Provisional Guardianship as a mechanism to reach the reasonable duration of the process. 2020. 163 pages Master - Law School, University of São Paulo, São Paulo, 2020.

\section{ABSTRACT}

We will study the Provisional Guardianships, from their appearance until the new garment given by the new civil procedural diploma, where it made possible magnificent innovation, translated in the possibility of the judge to provisionally and provisionally anticipate what may result in the sentence, as a mechanism to satisfy the fundamental right to a reasonable duration of the proceedings. Provisional tutelage, perfected and profoundly altered by the New Civil Procedure Code, accelerated the process and, above all, limited, as much as possible, the use, by the defendant, of the dynamics normally dragged from the process to prolong for a long time the effective jurisdictional provision, or at least made it possible, by safeguarding the evidence, to better balance the time burden borne by the parties. We will address since the constitutionalization of the process and the principles derived from this phenomenon, positivizing fundamental rights and guarantees, among others the reasonable duration of the process, incorporated by amendment $45 / 2004$, and introduced in article $5^{\circ}$, inserted LXXVIII, which combined the right of action inserted in the item $X X X V$, the Provisional Guardianship shall be constitutionally supported. It is intended to demonstrate the process as an instrument through which jurisdictional protection, historical background, slowness, and complete study of the new provisional protection will be carried out, emphasizing its historical origin, evolution, conceptualization, species, assumptions, reversibility and revocation, fungibility, time of concession, stabilization of tutelage, and how to use it in other countries, relating them to the fundamental right to a reasonable duration of the process, by studying the procedural time and the world context, innovations and structure that can guarantee the effective and swift jurisdictional provision.

KEYWORDS: Provisional Guardianship. Fundamental right. Reasonable duration of the process. New Civil Procedural Code. 


\section{SUMÁRIO}

1.1. A CONSTITUCIONALIZAÇÃO DO PROCESSO - NEOPROCESSUALISMO 16

1.2. PRINCÍPIOS CONSTITUCIONAIS DE DIREITO PROCESSSUAL __ 17

1.2.1. PRINCÍPIO DA GARANTIA DO DEVIDO PROCESSO LEGAL ___ 18

1.2.2. PRINCÍPIO DO CONTRADITÓRIO E AMPLA DEFESA. ___ 21

1.2.3. PRINCÍPIO DA ISONOMIA PROCESSUAL__ 24

1.2.4. PRINCÍ́IIO dA INAFASTABILIDADE DO CONTROLE JURISDICIONAL OU DIREITO DE AÇÃO.__ 27

1.2.5. PRINCÍPIO DO JUIZ NATURAL.

1.2.6. PRINCÍPIO DA PUBLICIDADE DOS ATOS PROCESSUAIS

1.2.7. PRINCÍPIO dA FUNDAMENTAÇÃO E MOTIVAÇÃO dAS DECISÕES JUdICIAIS _ 32

1.2.8 - PRINCÍPIO DO DUPLO GRAU DE JURISDIÇÃO___ 34

1.2.9 - PRINCÍPIO DA INADMISSÃO DA PROVA OBTIDA POR MEIO ILÍCITO __ 36

1.2.10 PRINCÍPIO DA DURAÇÃo RAZOÁVEL DO PROCESSO OU DA CELERIDADE PROCESSUAL. _ 39

2. O PROCESSO COMO INSTRUMENTO

2.1 EVOLUÇÃO HISTÓRICA DO PROCESSO

2.2 ASPECTOS RELEVANTES DA INSTRUMENTALIDADE____ 45

2.3. O PROBLEMA DA MOROSIDADE __ 51

3. DA TUTELA PROVISÓRIA

3.1 A ORIGEM DA TUTELA PROVISÓRIA _

3.2 EVOLUÇÃO HISTÓRICA NO BRASIL _ 55

3.3 CONCEITO

3.4 A FUNDAMENTO CONSTITUCIONAL DA TUTELA PROVISÓRIA _ 61

3.5 A CLASSIFICAÇÃO DA TUTELA PROVISÓRIA _ 64

3.6. TUTELA DE URGÊNCIA CAUTELAR E ANTECIPADA 66

3.6.1. ASPECTOS COMUNS DA TUTELA ANTECIPADA E DA TUTELA CAUTELAR

3.6.2 ASPECTOS DIFERENCIAIS ENTRE TUTELA ANTECIPADA E TUTELA CAUTELAR_

3.6.3 FUNGIBILIDADE ENTRE AS TUTELAS DE URGÊNCIAS

3.7. PRESSUPOSTOS GERAIS PARA CONCESSÃO DA TUTELA DE URGÊNCIA ___ 80

3.7.1 PROBABILIDADE DO DIREITO (FUMUS BUNI IURIS)

3.7.2 PERIGO DA DEMORA (PERICULUM IN MORA) _ 84

3.7.3 REQUISITO NEGATIVO - IRREVERSIBILIDADE__ 87

3.7.4 CAUÇÃO__ 91

3.8 MOMENTO DA CONCESSÃO DA TUTELA DE URGÊNCIA___ 92

3.8.1 CONCESSÃO DA TUTELA EM CARÁTER INCIDENTAL __ 94 
3.8.1.1 Concessão da tutela de urgência de forma liminar - inaudita altera parte 94

3.8.1.2 Outros Momentos Para a Concessão

3.8.2 TUTELA DE URGÊNCIA CAUTELAR OU ANTECIPADA REQUERIDA EM CARÁTER ANTECEDENTE

3.8.2.1 Tutela Antecipada Requerida em Caráter Antecedente

3.8.2.2 Da Estabilização Da Tutela Antecipada Requerida em Caráter Antecedente___ 102

3.9 REVOGACAO E MODIFICACAO DA TUTELA ANTECIPADA _ 104

3.10 TUTELA DE EVIDÊNCIA___ 108

3.11 AS MEDIDA PROVISÓRIAS NO CONTEXTO MUDIAL____ 114

3.11.1 NO DIREITO ITALIANO _ 115

3.11.2 No DIREITO ALEMÃO__ 117

3.11.3 NO DIREITO FRANCÊS 119

3.11.4 NO DIREITO PORTUGUÊS — 121

3.11.5 NO DIREITO ARGENTINO _ 123

3.11.6 NO DIREITO AMERICANO _ 124

4. DA RAZOÁVEL DURAÇÃO DO PROCESSO

4.1 O TEMPO E O PROCESSO 126

4.2 CRITÉRIOS PARA DETERMINAÇÃO DA RAZOÁVEL DURAÇÃO DO PROCESSO NA CORTE EUROPEIA

DE DIREITOS HUMANOS 129

4.3 DIREITO FUNDAMENTAL A RAZOÁVEL DURAÇÃO DO PROCESSO 131

4.4 CONVENÇÃO AMERICANA DE DIREITOS HUMANOS E SEUS REFLEXOS NA CF/88 134

4.5 A DURAÇÃO RAZOÁVEL DO PROCESSO NO CONTEXTO MUNDIAL _ 137

4.5.1 NO DIREITO ARGENTINO _ 138

4.5.2 NO DIREITO ESPANHOL 139

4.5.3 NO DIREITO AMERICANO _ 140

4.5.4 NO DIREITO ITALIANO _ 141

4.5.5 NOS DEMAIS PAÍSES DESENVOLVIDOS

4.6 A TUTELA PROVISÓRIA E A RAZOÁVEL DURAÇÃO DO PROCESSO. __ 143

4.7 A CELERIDADE PROCESSUAL VERSO A SEGURANÇA JURÍDICA

4.8 DOS PRAZOS PARA MANIFESTAÇÃO DO JUIZ _ 146

4.9 MODIFICAÇÕES QUE VISAM DAR CELERIDADE AO TRÂMITE PROCESSUAL __ 147

4.10 DA ESTRUTURA DO PODER JUDICIÁRIO _ 149

CONCLUSÃO $\quad 150$

REFERÊNCIAS BIBLIOGRAFICAS 


\section{INTRODUÇÃO}

A dissertação tem como escopo o estudo das Tutelas Provisórias, desde do seu aparecimento, operada pela Lei $n^{\circ} 8.952$ de 13 de dezembro de 1994, até a nova roupagem dada pelo Lei 13.105 de 15 de março de 2015, que instituiu o novo diploma processual civil brasileiro, possibilitando magnífica inovação, traduzida na possibilidade do julgador antecipar, provisoriamente e mediante requisitos, aquilo em que poderá redundar a sentença, ou evitando o perecimento do direito tutelado via tutela jurisdicional, assim criando um mecanismo de aceleração processual capaz de satisfazer o direito fundamental à razoável duração do processo.

Inicialmente, será abordado o Neoprocessualismo, corrente hermenêutica adotada pela novo Diploma Processual Civil, passando as normas constitucionais a serem o ponto de partida para a interpretação e a argumentação jurídica, assumindo um caráter fundamental, pois a partir do momento em que se contemplaram amplos direitos e garantias, tornam constitucionais os mais importantes fundamentos do direito material e processual, insculpindo com a positivação os princípios constitucionais do processo civil, os quais serão demonstrado no primeiro capítulo da presente dissertação, e que possibilitará a denominada constitucionalização do direito infraconstitucional. Deste modo, alterando, radicalmente, o modo de construção da exegese da norma jurídica, uma vez que a lei perdeu sua posição central como fonte do direito e passou a ser subordinada à Constituição, não valendo, por si só, mas somente se conformada com a Constituição e, especialmente, se adequada aos direitos fundamentais.

Logo, no segundo capítulo, pretende-se elaborar um estudo sobre a instrumentalização do processo, mecanismo fundamental é único pelo qual é resolvido, no âmbito do judiciário, o conflito de interesse qualificado pela pretensão resistida, através do conjunto sistematicamente ordenada em um procedimento, pautado pela garantia do contraditório e da ampla defesa, com emprego da jurisdição. Nele são entregues à parte vencedora o bem da vida tutelado através do provimento jurisdicional, o qual deverá atender aos princípios constitucionais norteadores de sua atuação. Abordaremos a evolução do processo, os aspectos relevantes de sua instrumentalidade e finalizamos o capítulo discorrendo sobra o maior problema do processo na atualidade no Brasil e no Mundo, que é a temida morosidade processual. 
Essa nova exegese adotada pelo novo código, enfatiza os princípios constitucionais processuais, em especial os relacionados com a tutela provisória e com a razoável duração do processo, os quais surgem quando infringidos por ocasião de uma incontroversa e a tutela de evidência é concedida, satisfazendo a garantia constitucional da duração razoável do processo, como veremos nesta dissertação.

No seguinte, o mais importante capítulo, e que dá sustentáculo ao desenvolvimento da presente dissertação, estudaremos a Tutela Provisória, iniciando com um breve levantamento histórico, com a finalidade de descobrir as causas que deram origem a este instituto, bem como sua evolução, passando desde sua origem dentro do Direito Romano, através dos chamados interditos, até a sua aplicação no mundo atual. Abordaremos a evolução legislativa desse medida de cognição sumária no Brasil, discorrendo os fundamentos constitucionais, e sobre a nova classificação adotada pelo novo Código de Processo Civil, com adoção do sincretismo processual, e o consequente desaparecimento do processo cautelar, dividindo-a em tutela de evidência e tutela de urgência; e esta, por sua vez, está subdividida em tutela de urgência antecipada, de natureza satisfativa e tutela de urgência cautelar, de ordem conservativa, as quais estudaremos suas peculiaridades; semelhanças; diferenças básicas; a fungibilidade; os novos requisitos; momento da concessão, em caráter incidental ou antecedente e a possibilidade de estabilização da decisão concessiva de tutela antecipada, resolvendo a lide antes do próprio início do processo; a possibilidade de modificação e revogação, sempre descrevendo como era disciplinadas do diploma processual revogado e como ficou no novo código; a tutela de evidência, que configura uma das mais importantes ferramentas de combate a morosidade processual e por fim o estudo comparado com os principais ordenamentos jurídicos no Mundo.

No último capítulo abordaremos a razoável duração do processo, iniciando com o estudo do tempo processual, e fixando critérios para determinação do tempo razoável de tramitação dos processos, a evolução e influencia da convenção americana de direitos humanos até sua inclusão como direito fundamental no nosso Estado Democrático de Direito, enfatizando o tempo de processo nos principais ordenamentos jurídicos do Mundo, e por fim busco apresentar as soluções para atenuar o tempo de processo, em especial e utilização das Tutelas Provisória para tal fim, com o emprego de algumas modificação e estrutura necessárias para a contemplação da tutela jurisdicional efetiva. 
Desse modo, procuraremos demonstrar que a técnica da tutela provisória visa distribuir de forma equitativa o ônus do tempo do processo entre as partes, entretanto, será preciso que os operadores do direito utilizem tal instrumento de forma adequada, compreendendo a sua importância, para o instituto possa prestar a tutela jurisdicional efetiva com a solução da lide em tempo hábil, e, assim, apresentando-se como um excelente mecanismos de realização do direito fundamental à razoável duração do processo (art. 5, LXXVIII CF/88), reduzindo e aniquilando o fantasma da morosidade do ordenamento jurídico. 


\section{CONCLUSÃO}

Foi constatado na presente dissertação que o surgimento do instituto das Tutela Provisórias veio ao encontro aos anseios de uma Justiça mais rápida e efetiva, ficando demonstrado que as medidas provisórias seja tutelas de urgência ou tutela de evidência, respeitado certos requisitos, buscam em sua finalidade, ao menos em tese, abreviação do tempo despendido no processo judicial entre a interposição da lide e a concretização do direito pleiteado em juízo. Neste sentido, insta destacar a imprescindibilidade dessas medidas para alcançarem o resguardo do direito material durante o tramite processual, possibilitando maior celeridade para o demandante da tutela jurisdicional.

Foi estudado no primeiro capítulo o Neoprocessualismo, e foi constatado que esse corrente hermenêutica foi a base de sustentáculo do Novo Diploma Processual Civil vigente, passando as norma constituição a serem o ponto de partida para a interpretação e a argumentação jurídica, assumindo um caráter fundamental, pois a partir do momento em que se contemplaram amplos direitos e garantias, tornam constitucionais os mais importantes fundamentos dos direitos material e processual, insculpindo com a positivação os princípios constitucionais do processo civil, os quais foram demonstrado e detalhados a sua importância e aplicabilidade no Ordenamento jurídico pátrio., com exegese da norma jurídica processual subordinada as garantia e princípios previstos na Constituição Federal.

No segundo capítulo foi abordado um amplo estudo sobre a instrumentalização do processo, mecanismo fundamental é único pelo qual é resolvido, no âmbito do judiciário, o conflito de interesse qualificado pela pretensão resistida, através do conjunto sistematicamente ordenada em um procedimento, pautado pela garantia do contraditório e da ampla defesa, com emprego da jurisdição. Foi verificado e estudado a evolução do processo, os aspectos relevantes de sua instrumentalidade e foi encerrado o capítulo discorrendo sobra o maior problema do processo na atualidade no Brasil e no Mundo, que é a temida morosidade processual.

No capítulo central da dissertação, foi estudado e bastante detalhado a Tutela Provisória, iniciando com um breve levantamento histórico, e descoberto a origem deste instituto, dentro do Direito Romano, nos interditos romanos, bem como foi 
verificado a sua evolução, passando desde sua origem até a sua aplicação no mundo atual, sendo enumeradas e citadas as evoluções legislativas, foi enfatizado os fundamentos constitucionais, e sobre a nova classificação adotada pelo novo Código de Processo Civil, com abolição do processo cautelar em virtude da adoção do sincretismo processual. No novo Código de Processo Civil foi verificado a divisão das Tutela Provisória em tutela de evidência e tutela de urgência, e está, por sua vez, foram subdivididas em tutela de urgência antecipada, de natureza satisfativo e tutela de urgência cautelar, de ordem conservativa, sendo estudado suas peculiaridades; semelhança; diferenças básicas; a fungibilidade; os requisitos; momento da concessão, em caráter incidental ou antecedente e novel possibilidade de estabilização da decisão concessiva de tutela antecipada, resolvendo a lido antes até do próprio início do processo. Foi analisada a possibilidade de modificação e revogação, abordando sempre a diferença entre o novo e o velho diploma processual civil; a tutela de evidência, que restou comprovado configurar uma excelente ferramenta de combate a morosidade processual e por fim estudado e verificado como tal instituto é utilizado nos principais ordenamentos jurídicos no Mundo.

No ultimo capítulo foi estudado à razoável duração do processo, e concluímos o estudo aprofundado do tempo processual se faz necessário e fundamental para ser definido o tempo razoável de tramitação dos processos. Também foi abordado a evolução e influencia da convenção americana de direitos humanos no nosso Estado Democrático de Direito, sendo enfatizado o tempo de processo nos principais ordenamentos jurídicos do Mundo, e por fim verificou as possibilidades de solucionar ou ao menos, atenuar o tempo de tramitação dos processos, com a utilização das Tutelas Provisória para esse fim, com auxilio mecanismo processuais e estruturais necessários para a contemplação uma tutela jurisdicional realmente efetiva.

Encerra-se a presente dissertação com a certeza de que os Tutelas Provisórias vai contribui para que haja uma maior efetividade na prestação jurisdicional, sendo capaz de impedir o perecimento do direito de quem busca a tutela, e mais, sendo extremamente útil na busca da repressão dos vários modos maliciosos protelatórios do andamento processual, prestando a tutela jurisdicional de forma efetiva e em tempo razoável. 


\section{REFERÊNCIAS BIBLIOGRAFICAS}

ACQUAVIVA, Marcos Cláudio. Dicionário Básico de Direito. 2. ed. São Paulo: Jurídica Brasileira, 1997.

ALARCÓN, Pietro de Jesús Lora; TAVARES, André Ramos; LENZA, Pedro Reforma do judiciário e efetividade da prestação jurisdicional. São Paulo: Método, 2005.

ALEXY, Robert. Conceito e validade do direito. São Paulo: Martins Fontes, 2009. . On the concept and the nature of law. Ratio Juris, Oxford.

ALVES, José Carlos Moreira. Direito Romano. Rio de Janeiro: Forense, 1971.

ALVIM, CARREIRA. Ação Monitória e temas polêmicos da reforma processual. Belo Horizonte: Del Rey, 1996.

ALVIM, Eduardo Arruda. Tutela Provisória. 2 ed. São Paulo: Saraiva, 2017.

AMARAL, Julio Ricardo de Paula. Tutela antecipada. São Paulo: São Paulo, 2001.

ANDRADE, Érico. A técnica processual da tutela sumária no direito italiano. Revista de Processo, vol. 179, p. 175-216. São Paulo: RT, Jan / 2010.

ANDRADE, Sérgio Monteiro de. Tutela Antecipada. Rio de Janeiro: Revista dos Tribunais, 1997.

ARAÚJO FILHO, Luiz Paulo da Silva. Da Antecipação da Tutela. Rio de Janeiro: Forense, 1996.

ARGENTINA. Corte Suprema de Justicia de la Nación da República Argentina. Caso Mattei, Angél. Velez Carreras, Ignacio y otros. Julgado em 29. nov. 1968. Disponível em: <http:// www.csjn.gov.ar/jurisp/jsp/MostrarSumario?id=370645\&indice=3>. Acesso em: 03 mar. 2019.

ARRUDA, Samuel Miranda. O direito fundamental à razoável duração do processo. Brasília: Brasília Jurídica, 2006.

ASSIS, Carlos Augusto de; LOPES, João Batista. Tutela Provisória: tutela antecipada; tutela cautelar; tutela de evidência; tutela inibitória antecipada. Brasília: Gazeta Jurídica, 2018.

BARBOSA, Carlos Eduardo Ferraz de Mattos. Processo Civil: Teoria Geral do Processo e Processo de Conhecimento. 3. ed. São Paulo: Saraiva, 2000.

BARCELLOS, Ana Paula de. Neoconstitucionalismo, Direitos Fundamentais e Controlo das Políticas Públicas. 2000. 
BARROSO, Luís Roberto. Interpretação E Aplicação Da Constituição Fundamentos De Uma Dogmática Constitucional Transformadora. 7 ed. São Paulo: Saraiva. 2009.

Saraiva, 2010.

Curso de Direito Constitucional Contemporâneo. 2 ed. São Paulo:

BARZOTTO, Luis Fernando. O positivismo jurídico contemporâneo: uma introdução a Kelsen, Ross e Hart. 2 ed. Porto Alegre: Livraria do Advogado, 2007.

BECCARIA, Cesare. Dos delitos e das penas. Tradução de J. Cretella Júnior e Agnes Cretella. 2. ed. São Paulo: Ed. Revista dos Tribunais, 1998.

BEDAQUE, José Roberto dos Santos. Tutela cautelar e tutela antecipada: tutelas de urgência (tentativa de sistematização). 2. ed. São Paulo: Malheiros, 2001.

BENEDUZI, Renato. Introdução ao Processo Civil Alemão. Salvador: Juspodivm, 2015.

BERALDO, Maria Carolina Silveira. O comportamento dos sujeitos processuais como obstáculo à razoável duração do processo. São Paulo: Saraiva, 2013.

BERMUDES, Sérgio. A reforma do Código de Processo Civil. 2. ed. São Paulo: Saraiva, 1996.

Bastos, 1995.

.A Reforma do Código de Processo Civil. Rio de Janeiro: Freitas

BERTOLO, José Gilmar. Tutela Antecipada: origem, princípios e diferenciações no direito positivo brasileiro. Leme: J. H. Mizuno, 2005.

BITTAR, Carlos Alberto. Metodologia da pesquisa jurídica: teoria e prática da monografia para os cursos de Direito. 14 ed. São Paulo: Saraiva, 2016.

BOBBIO, Norberto. O positivismo jurídico: lições de filosofia do direito. São Paulo: Ícone, 2006.

Teoria geral do direito. 3 ed. São Paulo: Martins Fontes, 2010.

BOUVIER, John. Bouvier's Law Dictionary and Concise Encyclopedia. 8. ed. 3. rev. v. 2. Nova York, 1984.

BRASIL, Superior Tribunal de Justiça. Recurso Especial n. ${ }^{\circ} 60.607-\mathrm{SP}-2^{\mathrm{a}} \mathrm{T}$. Relator: Ministro Ademar Maciel. Diário de Justiça da União, p. 49.929, de 04 setembro de 1997.

BRASIL, Supremo Tribunal Federal. Agravo Regimental n. ${ }^{\circ} 761-1$. Relator : Ministro Celso de Mello. Diário de Justiça da União, n. ${ }^{\circ}$ 106, p. 24.786, 6 junho de 1997. 
BRASIL. [Constituição (1988)]. Constituição da República Federativa do Brasil de 1988. Brasília, DF: Presidência da República, [2016]. Disponível em: http://www.planalto.gov.br/ccivil_03/Constituicao/ Constituiçao.htm. Acesso em: 3 fev. 2020.

BRASIL. Código de Processo Civil. Lei 13. 105, de 13 de Março de 2015. Disponível em <http://www.planalto.gov.br/ccivil 03/ ato2015-2018/2015/lei//13105.htm.> diversos acessos.

BRASIL. Código de Processo Penal. Decreto-lei n. 3.686, de 03 de outubro de 1941. BRASIL. Constituição (1988). Constituição da República Federativa do Brasil. Brasília, DF: Senado, 1988.

BRASIL. Decreto Legislativo n² 27, De 1992.

BRASIL. Lei de Introdução ao Código Civil. Decreto-Lei n. 4.657, de 4 de setembro de 1942.

BRASIL. Lei $\mathbf{n . ~ 8 . 9 5 2 , ~ d e ~} 13$ de dezembro de 1994.

BRASIL. Lei $\mathbf{n}^{\circ}$ 10.444, de 07 de maio de 2002.

BRASIL. Lei $\mathbf{n}^{\circ}$ 5.869, de 11 de janeiro de 1973.

BUENO, Cassio Scarpinella. Manual de direito processual civil. volume único. 4 ed. São Paulo: Saraiva, 2018.

2017.

. Novo Código de Processo Civil anotado. 3 ed. São Paulo: Saraiva, . Novo Código de Processo Civil anotado. São Paulo: Saraiva. 2015.

.Tutela provisória no novo CPC : dos 20 anos de vigência do art. 273 do $\overline{\mathrm{CPC} / 1973}$ ao CPC/2015. São Paulo: Saraiva, 2016.

Paulo: Saraiva, 2019.

Curso Sistematizado de direito processual civil. volume 2. 8 ed. São CAMARA, Alexandre Freitas. Lições de Direito processual civil. v1. 13 ed. Rio de Janeiro: Editora Lumen Júris. 2005.

. O novo processo civil brasileiro. São Paulo: Atlas, 2015.

CAMBI, Eduardo. Neoconstitucionalismo e Neoprocessualismo - Direitos Fundamentais, Políticas Públicas e Protagonismo Judiciário. São Paulo : Almedina, 2016.

CANOTILHO, J.J. Gomes. Direito Constitucional. 5a ed. Coimbra: Almedina, 1991. 
CAPPELLETTI, Mauro; GARTH, Bryant. Acesso à justiça. Trad. (Ellen Gracie Northfleet). Porto Alegre: Fabris, 1998.

CARBONELL, Miguel. Neoconstitucionalismo(s). Madrid: Trotta, 2003. . Teoria del Neoconstitucionalismo. Madrid: Trotta, 2007.

CARMIGNANI, Maria Cristina da Silva. A Origem Romana da Tutela antecipada. São Paulo: Revista dos Tribunais, 2001.

CARNEIRO, Athos Gusmão. Da antecipação de tutela. 6. ed. Rio de Janeiro: Forense, 2005.

CARNELUTTI, Francesco. Studi di diritto processuale. Padova: Cedam. 1925-1938.

CASCONI, Francisco Antônio. Tutela Antecipada nas Ações Possessórias. São Paulo: Juarez de Oliveira, 2001.

CASTRO, Leonardo Prieto. Derecho Processal Civil. Zaragoza: Livraria General , 1949. pág. 209

CHIOVENDA, Giuseppe. Instituições do direito processual. v. 2. Campinas: Bookseller, 1998.

COMANDUCCI, Paulo. Formas de (Neo)constitucionalismo: um análisis Metateórico, in

CORRÊA, Fábio Peixinho Gomes Corrêa. Governança Judicial. São Paulo: Quartier Latin, 2012.

DE PAOLIS, Maurizio. Eccessiva durata del processo: risarcimento del dano. II ed. Republica de San Marino, 2012.

DIAS, Gabriel Nogueira. Positivismo jurídico e a teoria geral do direito: na obra de Hans Kelsen. São Paulo: Revista dos Tribunais, 2010.

DIDIER JR, Fredie. Curso de Direito Processual Civil. Volume I. Salvador: Juspodivm, 2007.

Juspodivm, 2015.

.Curso de Direito Processual Civil: Volume 2. 10 ed. Salvador:

DIMOULIS, Dimitri. Positivismo jurídico: Introdução a uma teoria do direito e defesa do pragmatismo jurídico-político. São Paulo: Método, 2006.

DINAMARCO, Cândido Rangel. A Reforma da Reforma. 2 ed. São Paulo: Malheiros,. 2002. 
DINAMARCO, Candido Rangel. Nova era do processo civil. São Paulo: Malheiros, 2003.

DONIZETTI, Elpídio. Curso Direito Processual Civil. 23 ed. São Paulo: Atlas, 2020. FERES, Carlos Roberto. Antecipação da tutela jurisdicional. São Paulo: Saraiva, 1999.

FERRAZ JUNIOR, Tércio Sampaio. Teoria da norma jurídica. 4 ed. Rio de Janeiro: Forense, 2006.

FRIEDE, Reis. Comentários ao Código de Processo Civil. Rio de Janeiro: Forense Universitária, 1997.

Tutela Antecipada, Tutela Especifica e Tutela Cautelar. 2. ed. Belo Horizonte: Del Rey, 1996.

FUENTESECA, Pablo. Investigaciones de derecho procesal romano. Salamanca, 1969.

FURASTÉ, Pedro Augusto. Normas Técnicas para o Trabalho Cientifico. 8 ed. Porto Alegre: 2000.

FUX, Luiz. Tutela de Segurança e Tutela de Evidência (Fundamentos da Tutela Antecipada). São Paulo: Saraiva, 1996.

GALLI, Leandro. Antecipação dos Efeitos da Tutela e Satisfatividade. Curitiba: Revista dos Tribunais, 1999.

GARCIA DE ENTERRÍA, Eduardo. Democracia, jueces y control de la administración. Madrid: Civitas, 1995.

GARCIA, José Antônio Tomé Apud TUCCl, José Rogério Cruz e. Tempo e Processo. São Paulo: Editora Revista dos Tribunais. 1997.

GARCIA, José Antônio Tomé. Apud VIANA, Adriana Grandinetti. A razoável duração do processo como mecanismo de desenvolvimento social. 2007. Dissertação (Mestrado em Direito) - Pontifícia Universidade Católica do Paraná, Curitiba, 2007.

GIOLO JUNIOR, Cildo. Morosidade da justiça: a responsabilidade patrimonial do estado pela demora na entrega da prestação jurisdicional. Curitiba: Juruá, 2012.

GODINHO, Robson Renault.; CABRAL, Antonio do Passo; CRAMER, Ronaldo (coord.). Comentários ao novo Código de Processo Civil Rio de Janeiro: Forense, 2016.

GOMES, Frederico Augusto. A estabilização da tutela antecipada. São Paulo: Thomson Reuters Brasil, 2018. 
GONÇALVES, Marcus Vinícius Rios. Direito Processual Civil Esquematizado. $7^{a}$ ed. 2016.

GRINOVER, Ada Pellegrini. Novas Tendências do Direito Processual - de acordo com a Constituição de 1988. Rio de Janeiro: Forense Universitária, 1990.

GUERRA FILHO, Santigo Willis. Teoria da Ciência Jurídica. São Paulo: Saraiva.

GUERRA, Adriana Diniz de Vasconcellos. A Tutela Antecipada e sua Admissibilidade em Sede de Ação Rescisória. Rio de Janeiro: Forense, 2001.

GUERRA, Marcelo Lima. Estudos sobre o processo cautelar. 2. ed. São Paulo: Malheiros, 1997.

HART, H. L. A. O conceito de direito. São Paulo: Martins Fontes, 2009.

HERKENHOFF, João Baptista. O Direito Processual e o resgate do Humanismo. 2 ed. Rio de Janeiro: Thex Editora. 2001.

HERRERA, Edgardo López. Daños por demora irrazonable del proceso judicial. Disponível em: Disponível em: <http://www.taringa.net/posts/apuntes-ymonografias/7560119/Danos-por-Demora-irrazonable-del-ProcesoJudicial.html>.

Acesso em: 03. mar. 2019.

HOFFMAN, Paulo. Razoável duração do processo. São Paulo: Quartier Latin, 2006.

JOBIM, Marcos Félix. 0 direito à razoável duração do processo: responsabilidade civil do Estado em decorrência da intempestividade processual. 2 ed. Porto Alegre: Livraria do Advogado, 2012.

JUSTIÇA EM NÚMEROS 2019 DO CONSELHO NACIONAL DE JUSTIÇA - CNJ .Disponivel em < https://www.cnj.jus.br/wpcontent/uploads/conteudo/arquivo/2019/08/justica em numeros20190919.pdf.

Acessado em 15/02/2020.

KELSEN, Hans. Teoria purado direito. 7 ed. São Paulo: Martins Fontes, 2006.

LACERDA, Galiano. Tutela Antecipada e Tutela Interdital. Rio de Janeiro: Forense, 1997.

LACERDA, Gustavo Biscaia de. Augusto Comte e o positivismo redescobertos. Revista de Sociologia e Politica, Curitiba, v. 17, n. 34, out 2009.

LASPRO, Oreste Nestor de Souza. Duplo grau de jurisdição no direito processual civil. São Paulo: Revista dos Tribunais, 1995.

LASSALE, Ferdinand. O que é uma Constituição? Campinas: Servanda, 2010.

LEAL, Fabio Resende. A celeridade processual como pressuposto da efetividade dos direitos fundamentais. Curitiba: Juruá, 2011. 
LENZA, Pedro. Direito constitucional esquematizado. 20 ed. São Paulo: Saraiva, 2016.

LIEBMAN, Enrico Tullio. Manual de Direito Processual Civil. Trad. de Cândido Rangel Dinamarco. v. I, n. 41. Rio de Janeiro: Forense, 1984.

LOPES JR, Aury. Introdução crítica ao processo penal. (Fundamentos da Instrumentalidade Constitucional). 4. ed. Rio de Janeiro: Lumen Júris, 2006.

LOPES JR., Aury; BADARÓ, Gustavo Henrique. Direito ao processo penal no prazo razoável. 2.ed. Rio de Janeiro: Lumen Juris, 2009.

LOPES, João Batista. Tutela Antecipada no Processo Civil Brasileiro. São Paulo: Saraiva. 2001.

MACHADO, Antônio Cláudio Costa. Tutela Antecipada. São Paulo: Oliveira Mendes. 1998.

MACIEL, Adhemar Ferreira. O Bill of Right Americano - Reflexos no Direito Constitucional Brasileiro. Belo Horizonte: Del Rey, 2016.

MARIANO, João Cura. A Providência Cautelar de Arbitramento de Reparação Provisória. Coimbra: Almedina, 2006.

MARINONI, Luiz Guilherme e ARENHART, Sérgio Cruz. Manual do Processo de Conhecimento. 3. ed., São Paulo: Revista dos Tribunais, 2006.

MARINONI, Luiz Guilherme. A Antecipação da Tutela. 7 ed. São Paulo: Malheiros. 2002.

A Antecipação da tutela. 3. ed. São Paulo: Malheiros, 1997.

. Apud GUERRA, Adriane Diniz de Vasconcellos. A Tutela Antecipada e sua Admissibilidade em Sede de Ação Rescisória. Rio de Janeiro: Forense. 2001. Antônio Fabris Editor. 1994.

Efetividade do processo e tutela de urgência. Porto Alegre: Sergio . Teoria Geral do Processo. 3. ed. São Paulo: Revista os Tribunais, 2008.

. Tutela Antecipatória e Julgamento Antecipado: Parte incontroversa da demanda. 5 ed. São Paulo: Revista dos Tribunais. 2002.

MARINS, Victor A. A. Bomfim. Antecipação da tutela e tutela cautelar. Aspectos polêmicos da antecipação da tutela. São Paulo: RT, 1997.

MARQUES DE LIMA, Francisco Meton e MARQUES DE LIMA, Francisco Gérson. Reforma do Poder Judiciário. Comentários iniciais à EC 45/2004, Malheiros: São Paulo, 2005. 
MARTINS, Samir José Caetano. Neoconstitucionalismo e Relações Privadas: alguns parâmetros. Revista CEJ, v. 11, n. 36, p. 61-73, 2007.

MENDES, Gilmar Ferreira. Direitos Fundamentais e Controle de Constitucionalidade. 3 ed. São Paulo: Saraiva, 2004.

Curso de direito constitucional. 10 ed. São Paulo: Saraiva, 2015.

MENDONÇA, J. J. Florentino dos Santos. Acesso equitativo ao direito e à justiça. São Paulo: Almedina, 2016.

MENEZES, Cynara. As vitorias parciais contra a corrupção. Revista Veja, ed.1861. a. 37, n. 27, p. 36-39. São Paulo: Abril. 07 jul. 2004.

MORAES, Alexandre de. Direito constitucional. 18 ed., São Paulo: Atlas, 2005.

MOREIRA, José Carlos Barbosa. A Justiça no Limiar de Novo Século. In: Temas de Direito Processual. São Paulo: Saraiva, 1994.

.Temas de Direito Processual: Oitava Série. São Paulo: Editora Saraiva.

2004.

MORELLO, Augusto Mario. Antecipación de la tutela. La Plata: Platense, 1996.

MOTTA, Cristina Reindolf da. Due Process of Law. In: PORTO, Sérgio Gilberto (organizador). As garantias do Cidadão no Processo Civil: relações entre constituição e processo.

NERY JÚNIOR, Nelson; NERY, Rosa Maria de Andrade. Código de Processo Civil Comentado. 8 ed. São Paulo: Revista dos Tribunais, 2004.

. Princípios do processo civil na Constituição Federal. São Paulo: Revista dos Tribunais, 2002.

$\overline{\text { Tribunais, } 1995 .}$

Atualidades sobre o processo civil. São Paulo: Revista dos

Atualidades sobre o processo civil. 2. ed. São Paulo: RT, 1996.

. Princípios do Processo na Constituição Federal: Processo Civil.

Penal Administrativo. 9 ed. São Paulo: Revista dos Tribunais. 2009.

2004.

Teoria geral dos recursos. 6. ed São Paulo: Revista dos Tribunais,

NEVES, Daniel Amorim Assumpção. Manual de direito processual civil -Volume único.8. ed. Salvador: JusPodivm, 2016. 
NICOLITT, André. A duração Razoável do Processo. 2 ed. São Paulo: Revista dos Tribunais, 2014.

NUNES JÚNIOR, Flávio Martins Alves. Curso de direito constitucional. 3 ed. São Paulo: Saraiva, 2019.

OLIVEIRA, Vallisney de Souza, 0 juiz e o novo Código de Processo Civil. 1 ed. Curitiba: crv, 2016.

Organização dos Estados Americanos, Convenção Americana de Direitos Humanos, 1969 . Disponível em e https://www.cidh.oas.org/basicos/portugues/c.convencao americana.htm. >. diversos acessos.

PAES, S.M. S. Direito a ser ouvido em um prazo razoável. Morosidade da justiça segundo a ótica do tribunal europeu de direitos humanos. Revista de Informação Legislativa, Brasília, ano 34, n.135, p.3, jul./set. 1997.

PAJARDI, Piero. I provvedimenti d'urgenza tipici nel processo civile. 2. ed. Milão: Pirola, 1993.

PASSOS, José. Joaquim. Calmon de. Inovações no Código de Processo Civil. Rio de Janeiro: Forense, 1995.

PAULO, Vicente; ALEXANDRINO, Marcelo. Direito constitucional descomplicado. Niterói: Ímpetos, 2007.

PERROT, Roger. Les mesures provisoires en droit français. Les mesures provisoires en procédure civile. Atti del Colloquio Internazionale. Milano, 12-13 ottobre 1984 (org. professor Giuseppe Tarzia). Milão: Giuffrè, 1985.

PINHO, Humberto Dalla Bernardina de. Manual de direito processual civil contemporâneo. 2 ed. São Paulo: Saraiva, 2020.

PINTO, Rui. A Questão de Mérito na Tutela Cautelar. A obrigação genérica de não Ingerência e os limites da Responsabilidade Civil. Coimbra: Coimbra Editora. 2009.

POVEDA VELASCO, Ignácio Maria. A boa-fé na formação dos contratos (direito romano). In: Obrigações e contratos[S.I: s.n.], v. 3. , 2011.

RAMOS, Carlos Henrique. Processo civil e o princípio da duração razoável do processo. Curitiba: Juruá, 2008.

REGO, Carlos Francisco de Oliveira Lopes do. Comentários ao Código de Processo Civil. Coimbra: Almedina, 1999.

RIBEIRO, Leonardo Ferres da Silva. Tutela provisória: tutela de urgência e tutela de evidência do CPC/73 ao CPC/15. São Paulo: RT, 2015. 
$\mathrm{RICCl}$, Edoardo. A tutela antecipatória no direito italiano. Revista de Direito Processual Civil. Curitiba: Gênesis, v. 4, 1997.

RODRIGUES, Marcelo Abelha. Elementos do Direito processual civil. v 1. 3 ed. São Paulo: Editora Revista dos Tribunais. 2003.

ROJAS, Jorge A. Una cautela atípica. Revista de Derecho Procesal. Buenos Aires: Rubinzal-Culzoni, n. 1,1996.

SAMPAIO JÚNIOR, José Herval. Tutelas de urgência: sistematização das liminares. São Paulo: Atlas, 2011.

SANTORO, Gláucia Carvalho. Tutela Antecipada: a solução. Rio de Janeiro: Forense, 2000.

SANTOS, Boaventura de Souza. Os Tribunais nas Sociedades Contemporâneas: o caso Português. Porto: Afrontamento, 1996.

SANTOS, Jean Carlos Pimentel dos. Tutela Provisória e razoável duração do processual: aspectos relevantes. Revista dos Tribunais. Vol. 994. p. 501-524. São Paulo: RT, agosto 2018.

SANTOS, Welder Queiroz dos. Princípio do contraditório e vedação de decisão surpresa. Rio de Janeiro: Forense, 2018.

SCARPELLI, Natália Cançado. Estabilização da tutela provisória de urgência antecipada requerida em caráter antecedente. 2016. 186 f. Dissertação (Mestrado em Direito Processual Civil) - Pontifícia Universidade Católica de São Paulo (PUCSP), São Paulo, 2016.

SCHIMIT, Carl. Teoria de la Constituición. Munchen. Madrid: Editora Revista de Derecho Privado, 1928.

SCHINKI, Luiza. O Novo CPC e as Inovações no Instituto das "Condições das Ações, 2016. Acesso em 24/06/2018.

SEVERINO, Antônio Joaquim. Metodologia do Trabalho Cientifico. 22. ed. São Paulo: Cortez, 2002.

SILVA, De Plácido e. Vocabulário Jurídico. 11 ed. Rio de Janeiro: Forense, 1989.

SILVA, Ivan de Oliveira. A morosidade processual e a responsabilidade civil do Estado. São Paulo:Pillares, 2004.

SILVA, José Afonso. Curso de Direito Constitucional Positivo. 29a ed. São Paulo: Malheiros, 2007.

SILVA, Ovídio A. Baptista da. Curso de processo civil: processo cautelar (tutela de urgência), v.3 2.ed., rev. e atual. Rio de Janeiro: Forense, 1998. 
Paulo: Saraiva, 1996.

A Antecipação da Tutela na Recente Reforma Processual. São . Comentários ao Código de Processo Civil. 2 ed. São Paulo. 1986.

SLAIBI FILHO, Nagib. Direito Constitucional. Rio de Janeiro: Forense. 2005. p. 19. Reforma da justiça: notas à Emenda Constitucional n. 45, de 8 de dezembro de 2004. Rio de Janeiro: Ed. Ímpetus, 2005.

SOUZA NETO, Cláudio Pereira de. SARMENTO, Daniel. Direito Constitucional Teoria, história e métodos de trabalho, Belo Horizonte: Fórum, 2011.

SOUZA, Artur César de. Tutela Provisória - Tutela de Urgência e Tutela de Evidência. Coimbra/PT: Almedina, 2016.

STRECK, Lenio Luiz. Verdade e consenso: constituição, hermenêutica e teorias discursivas. 4 ed. São Paulo: Saraiva.

TAVARES, André Ramos. Curso de direito constitucional. 18 ed. São Paulo: Saraiva, 2020.

TAVARES, Fernando Horta(coord).Urgência de Tutela. Curitiba: Juruá. 2007.

THEODORO JUNIOR, Humberto; Andrade, Érico. A autonomização e a estabilização da tutela de urgência no projeto do CPC. Revista de Processo. São Paulo: RT, 2012.

Curso de Direito Processual Civil: Volume I Teoria Geral do Processo Civil, Processo de Conhecimento, Procedimento Comum. 55 ed. Rio de Janeiro: Forense, 2015.

Janeiro: Forense, 2016.

Curso de Direito Processual Civil. 56 ed. Vol. 1. Rio de Curso de Direito Processual Civil. Vol. II. 31 ed. São Paulo:

Forense, 2001.

O cumprimento das medidas cautelares. Doutrinas essenciais do processo civil. v. 5. São Paulo: RT, 2011.

TRIVIÑOS, Augusto Nibaldo Silva. Introdução à pesquisa em ciências sociais: a pesquisa qualitativa em educação. 3 ed. São Paulo: Atlas, 1992.

TUCCI, José Rogério Cruz e. Garantia do processo sem dilações indevidas. Revista Jurídica, n. 277, 2000.

.Tempo e Processo. São Paulo: Editora Revista dos Tribunais. 1997. 
TUCCI, Rogério Lauria e José Rogério Cruz. Constituição de 1988 e processo: regramentos e garantias constitucionais do processo. São Paulo: Saraiva, 1989.

VINCENT, Jean; MONTAGNIER, Gabriel; VARINARD, André. Le Justice et ses Institutions. Paris: Dalloz, 1982.

WAMBIER, Luiz Rodrigues e Teresa Arruda Alvim, MEDINA, José Miguel Garcia. Breves comentários à nova sistemática processual civil. 3 ed. São Paulo: Editora Revista dos Tribunais. 2005.

WAMBIER, Luiz Rodrigues e WAMBIER, Teresa Arruda Alvim. Breves Comentários à $2^{\circ}$ Fase da Reforma do Código de Processo Civil. São Paulo: Revista dos Tribunais, 2 ed, 2002.

WAMBIER, Teresa Arruda Alvim et al. [Coords.]. Breves comentários ao Novo Código de Processo Civil. São Paulo: RT, 2015.

Comentário ao Código de Processo Civil, Lei n. ${ }^{\circ}$ 5.869, de 11 de janeiro de 1973. Vol. V. arts. 476 a 565. Rio de Janeiro: Forense, 2006.

Reforma do Judiciário: Primeiras reflexões sobre a emenda constitucional n.45/2004. São Paulo: Editora Revista dos Tribunais. 2005.

YARSHELL, Flávio Luiz. Tutela Jurisdicional. 2 ed. São Paulo: DPJ Editora, 2006.

ZANFERDINI, Flávia de Almeida Montingelli. A Crise da Justiça e do Processo e a Garantia do Prazo Razoável. Revista de Processo, n. 112, out/dez 2003.

ZAVASCKI, Teori Albino. Antecipação da Tutela. 3 ed. São Paulo: Saraiva, 2000.

.Antecipação de tutela e colisão de direitos fundamentais. In: Reforma do Código de Processo Civil - obra coletiva, coordenação de Sálvio de Figueiredo Teixeira. São Paulo: Saraiva, 1996. 